\title{
ANALISIS PREFERENSI KONSUMEN TERHADAP PEMBELIAN KOPI INSTAN WHITE COFFEE DI KECAMATAN KEBUMEN KABUPATEN KEBUMEN
}

\author{
Jivana Zulfi, Kusnandar, Rr. Aulia Qonita \\ Program Studi Agribisnis, Fakultas Pertanian, Universitas Sebelas Maret Surakarta \\ Jalan Ir. Sutami No. 36 A Kentingan Surakarta 57126 Telp./Fax (0271) 637457 \\ E-mail : jivana@student.uns.ac.id
}

\begin{abstract}
This research was aimed to determine the consumer preferences and attributes that most consumers consider in purchases of instant White Coffee in Kebumen Subdistrict Kebumen Regency. The basic method of this research is descriptive analytic by survey technique to the respondents directly. This research was conducted to respondents who had bought instant White Coffee with 96 respondents. The sampling technique was done with convenience sampling technique use questionnaires. Data analysis used is chi square operated by SPSS and fishbein multi attribute analysis. Based on the research results obtained the following conclusions: (1) consumer's preference toward purchasing of instant white coffee purchase in Kebumen Subdistrict Kebumen Regency based on the existing attribute is flavor variant $=$ original $;$ promotion $=$ purchase bonus; packaging = attractive appearance; and guarantee = halal; as well as the preferred product is Luwak White Koffie; and (2) The attributes of instant white coffee most considered in the purchase decision of instant white coffee in Kebumen Subdistrict Kebumen Regency are brand attributes.
\end{abstract}

\section{Keywords : Chi Square, Consumer Preferences, Fishbein Multi attribute, Instant White Coffee, Product Attributes.}

\begin{abstract}
Abstrak : Penelitian ini bertujuan untuk mengetahui preferensi konsumen dan atribut yang paling dipertimbangkan konsumen terhadap pembelian kopi instan White Coffee di Kecamatan Kebumen Kabupaten Kebumen. Metode dasar penelitian ini adalah deskriptif analitik dengan teknik survei kepada responden secara langsung. Penelitian ini dilakukan kepada responden yang pernah membeli kopi instan White Coffee dengan jumlah 96 orang.Teknik pengambilan sampel dilakukan dengan convenience sampling menggunakan kuesioner. Analisis data yang digunakan adalah chi square yang dioperasikan melalui program SPSS dan analisis multi atribut fishbein. Berdasarkan hasil penelitian diperoleh kesimpulan sebagai berikut : (1) Preferensi konsumen terhadap pembelian kopi instan White Coffee di Kecamatan Kebumen Kabupaten Kebumen berdasarkan atribut yang ada yaitu varian rasa = original; promosi $=$ bonus pembelian; kemasan $=$ tampilan menarik; dan jaminan = halal; serta produk yang disukai adalah merek Luwak White Koffie; dan (2) Atribut kopi instan White Coffee yang paling dipertimbangkan dalam keputusan pembelian kopi instan White Coffee di Kecamatan Kebumen Kabupaten Kebumen adalah atribut merek.
\end{abstract}

Kata kunci : Atribut Produk,Chi Square,Kopi Instan White Coffee, Multi atribut Fishbein, Preferensi Konsumen.

\section{PENDAHULUAN}

Kopi instan merupakan produk yang praktis untuk dikonsumsi. Kopi instan diproduksi karena adanya perubahan pola konsumsi masyarakat menuju ke arah yang lebih praktis. Perubahan pola makan atau minum tersebut biasanya terjadi pada masyarakat perkotaan. 
Sebagian besar dari mereka telah disibukkan oleh pekerjaan yang menyita banyak waktu. Produk kopi instan yang kini telah diproduksi para produsen, merupakan salah satu solusi untuk memenuhi keinginan konsumen kopi

Inovasi terbaru dari kategori produk kopi adalah munculnya produk White Coffee dalam kemasan instan. Munculnya kopi instan White Coffee menciptakan persaingan yang semakin ketat antara para produsen kopi instan yang ditandai dengan munculnya merek-merek barukopi instan White Coffee. Hal tersebut merupakan hal yang wajar dalam bisnis sebab segala sesuatu yang terkait dengan produk yang populer akan menimbulkan munculnya pesaing baru dalam produk sejenis.

Semakin ketatnya persaingan di pasar minuman kopi khususnya kopi instan White Coffee, ditunjukkan dengan gencarnya masingmasing perusahaan untuk menarik perhatian calon konsumen melalui komunikasi pemasaran. Produsen perlu mengetahui selera konsumen dalam menentukan pilihan suka atau tidak suka seorang konsumen terhadap suatu produk. Hal ini dikarenakan, sebelum konsumen memutuskan untuk membeli suatu produk, terlebih dahulu mereka memperhatikan dan mempertimbangkan ciri-ciri fisik atau atribut yang melekat pada produk tersebut sesuai dengan kesukaan mereka untuk memperoleh kepuasan.

Setiap individu memiliki preferensi dalam menentukan berbagai pilihan untuk memenuhi kebutuhannya. Di dalam memenuhi kebutuhannya, konsumen pasti memiliki kendala-kendala yang dihadapinya seperti pendapatan yang dimiliki, waktu, selera, dan kendala lainnya (Arianty dan Rohmana, 2012). Preferensi konsumen didefinisikan sebagai selera subjektif (individu), yang diukur dengan utilitas, dari berbagai barang (Indarto, 2011). Preferensi konsumen muncul pada tahap dimana konsumen dihadapkan dengan berbagai macam pilihan produk maupun jasa dengan berbagai macam atribut yang berbeda-beda (Putri dan Iskandar, 2014). Menurut Zamhir (2014), preferensi terhadap suatu produk dapat berarti kesukaan, pilihan terhadap suatu merek yang lebih di inginkan setiap konsumen. Preferensi ini terbentuk atas persepsi terhadap merek salah satu produk atau jasa. Konsumen memilih produk berdasarkan atas informasi yang mereka dapat dan pengalaman yang sudah mereka terima (Marion, 2015).

Penelitian ini dilakukan untuk mengetahui preferensi konsumen dan atribut yang paling dipertimbangkan oleh konsumen terhadap pembelian kopi instan White Coffee. Atribut-atribut yang digunakan dalam penelitian ini yaitu varian rasa, promosi, kemasan, jaminan, dan merek. Melalui pengetahuan tentang atribut-atribut kopi instan White Coffee yang menjadi preferensi konsumen maka para produsen dan pemasar diharapkan akan lebih mudah untuk memasarkan dan menentukan strategi pemasaran yang tepat bagi produknya karena telah disesuaikan dengan kesukaan konsumen.

\section{METODE PENELITIAN}

Penelitian dilakukan pada bulan Januari 2017 sampai dengan Februari 2017 menggunakan metode dasar penelitian deskriptif analitik dengan menyusun data yang terkumpul, dijelaskan, dianalisis dan selanjutnya disimpulkan serta didukung teori-teori dari hasil penelitian terdahulu yang ada (Surakhmad, 2004) menggunakan teknik survei dalam pengumpulan data. Populasi dalam penelitian ini adalah semua orang di Kecamatan Kebumen yang pernah membeli kopi instan White Coffee. Sedangkan sampel penelitian ini berjumlah 96 orang. Pengambilan sampel menggunakan metode convenience sampling yang didasarkan pada kemudahan peneliti dalam menemukan responden serta bersedia menjadi responden dan dijadikan sampel (Darmawan, 2013).Kriteria responden dalam penelitian ini adalah responden yang membeli kopi instan White Coffee untuk dikonsumsi sendiri dan tidak untuk dijual kembali dengan metode analisis data chi square dan multi atribut fishbein.

\section{HASIL DAN PEMBAHASAN}

Pada analisis chi square akan diperoleh nilai $\mathrm{X}^{2}$ hitung yang nantinya akan dibandingkan dengan $X^{2}$ tabel. Apabila $X^{2}$ hitung $<X^{2}$ tabel, maka $\mathrm{H}_{0}$ diterima. Sedangkan apabila $X^{2}$ hitung $>\mathrm{X}^{2}$ tabel maka $\mathrm{H}_{0}$ ditolak.

Berdasarkan analisis chi square dapat diketahui bahwa terdapat perbedaan preferensi konsumen dalam membeli kopi instan White 
Coffee di Kecamatan Kebumen Kabupaten Kebumen. Hal ini dikarenakan setiap konsumen dalam melakukan pembelian kopi instan White Coffee memiliki pertimbangan yang berbeda-beda terhadap atribut yang melekat sesuai dengan selera atau kesukaan mereka, sehingga akan berpengaruh terhadap pengambilan keputusan dalam pembelian kopi instan White Coffee.

Adanya berbagai merek kopi instan White Coffee di pasaran menyebabkan konsumen menghadapi berbagai pilihan produk, terlebih dengan adanya varian rasa yang ditawarkan dari produk tersebut.Varian rasa diartikan sebagai variasi alternatif rasa yang ditawarkan kepada konsumen.

Tabel 1. Preferensi Konsumen terhadap Varian Rasa Kopi Instan White Coffee di Kecamatan Kebumen

\begin{tabular}{lccc}
\hline \multicolumn{1}{c}{ Varian rasa } & $\sum$ & $\begin{array}{c}\text { Nilai } \mathrm{X}^{2} \\
\text { hitung }\end{array}$ & $\begin{array}{c}\text { Nilai } \mathrm{X}^{2} \\
\text { tabel }\end{array}$ \\
\hline Original & 64 & & \\
Mocca & 27 & 55,563 & 5,991 \\
Karamel & 5 & & \\
\hline
\end{tabular}

Sumber : Analisis Data Primer, 2017

Berdasarkan Tabel 1 dapat diketahui preferensi konsumen terhadap varian rasa kopi instan White Coffe. Nilai chi square $\left(\mathrm{X}^{2}\right)$ yang diperoleh adalah sebesar 55,563. Nilai chi square $\left(\mathrm{X}^{2}\right)$ tersebut signifikan pada tingkat kepercayaan $95 \%$, dimana $X^{2}$ hitung lebih besar daripada $\mathrm{X}^{2}$ tabel. Hal ini berarti ada perbedaan yang nyata pada preferensi konsumen terhadap varian rasa kopi instan White Coffee pada tingkat signifikansi 5\% yang dapat dilihat pada Tabel 1. Varian rasa kopi instan White Coffee yang disukai konsumen adalah varian rasa original. Ketersediaan varian rasa produk kopi instan White Coffee sangatlah penting bagi konsumen yang memiliki preferensi yang berbeda terhadap varian rasa kopi instan White Coffee. Adanya berbagai varian rasa suatu produk merupakan strategi diversifikasi produk. Diversifikasi produk merupakan salah satu cara untuk meningkatkan volume penjualan yang dapat dilakukan oleh perusahaan terutama jika perusahaan tersebut telah berada dalam tahap kedewasaan. Menurut Khamidi (2013), melalui diversifikasi produk, suatu perusahaan tidak akan bergantung pada satu jenis produknya saja, tetapi perusahaan juga dapat mengandalkan jenis produk diversifikasinya, karena jika salah satu jenis produknya tengah mengalami penurunan, maka akan dapat teratasi dengan produk jenis lainnya.

Promosi yang tepat merupakan salah satu strategi pemasaran yang efektif, karena dengan melakukan promosi produsen dapat membujuk konsumen membeli produk yang ditawarkan. Kopi instan White Coffee merupakan produk baru di pasar dan kini telah banyak produsen kopi instan yang memproduksi kopi instan White Coffee. Oleh karena itu, promosi merupakan kegiatan yang perlu dilakukan agar produk dikenal, dicoba, dan kemudian dibeli oleh konsumen.

Tabel 2. Preferensi Konsumen terhadap Promosi Kopi Instan White Coffee di Kecamatan Kebumen

\begin{tabular}{lccc}
\hline \multicolumn{1}{c}{ Promosi } & $\sum$ & $\begin{array}{c}\text { Nilai } X^{2} \\
\text { hitung }\end{array}$ & $\begin{array}{c}\text { Nilai } X^{2} \\
\text { tabel }\end{array}$ \\
\hline $\begin{array}{l}\text { Bonus } \\
\text { pembelian }\end{array}$ & 76 & & \\
$\begin{array}{l}\text { Menyediakan } \\
\text { sampel }\end{array}$ & 20 & 32,667 & 3,841 \\
\hline
\end{tabular}

Sumber : Analisis Data Primer, 2017

Berdasarkan Tabel 2 dapat diketahui preferensi konsumen terhadap promosi kopi instan White Coffee. Nilai chi square $\left(\mathrm{X}^{2}\right)$ yang diperoleh adalah sebesar 32,667. Nilai chi square $\left(\mathrm{X}^{2}\right)$ tersebut signifikan pada tingkat kepercayaan $95 \%$, dimana $X^{2}$ hitung lebih besar daripada $\mathrm{X}^{2}$ tabel. Hal ini berarti ada perbedaan yang nyata pada preferensi konsumen terhadap promosi kopi instan White Coffee pada tingkat signifikansi 5\% yang dapat dilihat pada Tabel 2. Promosi yang disukai konsumen adalah promosi dengan cara memberikan bonus dalam pembelian. Bonus yang dimaksudkan adalah adanya pemberian penambahan jumlah produk. Menurut Hedynata dan Radianto (2016), promosi penjualan harus dilakukan dan ditingkatkan untuk dapat lebih meningkatkan penjualan produk. Ahli marketing menyatakan bahwa promosi penjualan adalah salah satu cara untuk membuat konsumen menjadi membeli dan melakukan pembelian ulang. Bentuk promosi 
penjualanyang sebaiknya dilakukan dan ditingkatkan promosi berdasarkan keinginan konsumen dan pendapat reseller, agen distributor, dan ahli marketing adalah seperti promosi buy 1 get 1 free ataupun free tester.

Kemasan merupakan atribut yang dapat meningkatkan citra produk di mata konsumen terutama dari segi penampilan. Kemasan yang baik merupakan elemen produk yang dapat mendorong konsumen untuk membeli suatu produk. Sebelum mencoba kopi instan White Coffee, pembeli akan menangkap kesan yang dikomunikasikan pada kemasan terlebih dulu.

Tabel 3. Preferensi Konsumen terhadap Kemasan Kopi Instan White Coffee di Kecamatan Kebumen

\begin{tabular}{lccc}
\hline \multicolumn{1}{c}{ Kemasan } & $\sum$ & $\begin{array}{c}\text { Nilai } \mathrm{X}^{2} \\
\text { hitung }\end{array}$ & $\begin{array}{c}\text { Nilai } \mathrm{X}^{2} \\
\text { tabel }\end{array}$ \\
\hline $\begin{array}{l}\text { Tampilan } \\
\text { kemasan } \\
\text { menarik }\end{array}$ & 46 & & \\
$\begin{array}{l}\text { Kualitas } \\
\text { kemasan tahan }\end{array}$ & 9 & 25,188 & 5,991 \\
$\begin{array}{l}\text { lama } \\
\text { Memuat } \\
\text { informasi } \\
\text { lengkap }\end{array}$ & 41 & & \\
\hline
\end{tabular}

Sumber : Analisis Data Primer, 2017

Berdasarkan Tabel 3 dapat diketahui preferensi konsumen terhadap kemasan kopi instan White Coffee. Nilai chi square $\left(\mathrm{X}^{2}\right)$ yang diperoleh adalah sebesar 25,188. Nilai chi square $\left(\mathrm{X}^{2}\right)$ tersebut signifikan pada tingkat kepercayaan $95 \%$, dimana $X^{2}$ hitung lebih besar daripada $X^{2}$ tabel.Hal ini berarti ada perbedaan yang nyata pada preferensi konsumen terhadap kemasan kopi instan White Coffee pada tingkat signifikansi 5\% yang dapat dilihat pada Tabel 3. Kemasan yang disukai oleh konsumen adalah kemasan yang menarik. Tampilan kemasan yang menarik pada suatu produk meliputi warna, logo produk, ilustrasi, teks, maupun tata letak yang sesuai Nuryanti dan Rahman (2008) menjelaskan bahwa desain kemasan sebuah produk merupakan bagian penting dari sebuah produk, yang akan menentukan apakah pembeli akan mengambil produk tersebut untuk dibeli atau tidak. Terdapat banyak produk di pasar yang siap untuk dijual, hanya kemasan produk yang menariklah yang akan menentukan potensi orang akan mengambil dan membelinya.

Jaminan merupakan atribut yang penting bagi suatu produk karena terkait dengan pertanggungjawaban produsen kepada konsumen. Konsumen wajib mendapatkan jaminan atas produk yang mereka beli.

Tabel 4. Preferensi Konsumen terhadap Jaminan Kopi Instan White Coffee di Kecamatan Kebumen

\begin{tabular}{lccc}
\hline Jaminan & $\sum$ & Nilai $^{2}$ & Nilai X $^{2}$ \\
\hline Halal & 75 & \multirow{2}{*}{30,375} & 3,841 \\
BPOM & 21 & & \\
\hline
\end{tabular}

Sumber : Analisis Data, 2017

Berdasarkan Tabel 4 dapat diketahui preferensi konsumen terhadap jaminan kopi instan White Coffee. Nilai chi square $\left(\mathrm{X}^{2}\right)$ yang diperoleh adalah sebesar 30,375. Nilai chi square $\left(\mathrm{X}^{2}\right)$ tersebut signifikan pada tingkat kepercayaan $95 \%$, dimana $X^{2}$ hitung lebih besar daripada $\mathrm{X}^{2}$ tabel. Hal ini berarti ada perbedaan yang nyata pada preferensi konsumen terhadap jaminan kopi instan White Coffee pada tingkat signifikansi 5\% yang dapat dilihat pada Tabel 4. Jaminan yang disukai oleh konsumen adalah adanya jaminan halal pada produk kopi insan White Coffee. Menurut Kurniawan (2014), untuk memberikan keyakinan kepada konsumen bahwa produk yang dikonsumsi adalah halal, maka perusahaan perlu memiliki sertifikat halal. Pasal 10 Ayat 1 Peraturan Pemerintah Republik Indonesia Nomor 69 tahun 1999 tentang label pangan yang menyatakan bahwa: "setiap orang yang memproduksi atau memasukkan pangan yang dikemas ke dalam wilayah Indonesia untuk diperdagangkan dan menyatakan bahwa pangan tersebut halal bagi umat Islam, bertanggung jawab atas kebenaran pernyataan tersebut dan wajib mencantumkan keterangan atau tulisan halal pada label". Ketentuan tersebut ditujukan untuk menunjang jaminan kehalalan bagi konsumen muslim, karena mengkonsumsi makanan dan minuman halal bagi pemeluk Islam tidak sebatas memenuhi kebutuhan hidup saja tapi merupakan bentuk aplikasi ajaran agama.

Merek diartikan sebagai pengaruh dari produk atau produsen yang menghasilkan 
produk ini di mata konsumen, dan pengaruhnya terhadap keputusan pembelian kopi instan White Coffee oleh konsumen.

Tabel 5. Merek Produk Kopi Instan White Coffee yang Disukai Responden di Kecamatan Kebumen

\begin{tabular}{lccc}
\hline \multicolumn{1}{c}{ Merek } & $\sum$ & $\begin{array}{c}\text { Nilai } X^{2} \\
\text { hitung }\end{array}$ & $\begin{array}{c}\text { Nilai X } \\
\text { tabel }\end{array}$ \\
\hline $\begin{array}{l}\text { Luwak } \\
\text { White Koffie }\end{array}$ & 78 & & \\
$\begin{array}{l}\text { Kopiko } \\
\text { White Coffee }\end{array}$ & 3 & 101,438 & 5,991 \\
$\begin{array}{l}\text { ABC } \\
\text { White Coffee }\end{array}$ & 15 & & \\
\hline
\end{tabular}

Sumber : Analisis Data Primer, 2017

Berdasarkan Tabel 5 dapat diketahui preferensi konsumen terhadap merek produk kopi instan White Coffee. Nilai chi square $\left(\mathrm{X}^{2}\right)$ yang diperoleh adalah sebesar 101,438. Nilai chi square $\left(\mathrm{X}^{2}\right)$ tersebut signifikan pada kepercayaan $95 \%$, dimana $X^{2}$ hitung lebih besar daripada $\mathrm{X}^{2}$ tabel. Hal ini berarti ada perbedaan yang nyata pada preferensi konsumen terhadap merek produk kopi instan White Coffee pada tingkat signifikansi 5\% yang dapat dilihat pada Tabel 5. Berdasarkan TOP Brand Award fase 1 tahun 2017, produk Luwak White Koffie dan ABC White Coffee masingmasing menempati peringkat satu dan dua serta memperoleh predikat TOP Brand untuk kategori minuman White Coffee dengan TOP Brand Index masing-masing $68,5 \%$ dan $15,3 \%$.
Adanya predikat TOP Brand terhadap suatu merek produk menujukkan bahwa merek produk tersebut terkenal di pasar dan dikenal konsumen. Keberhasilan merek suatu produk dalam memperoleh kepercayaan dari konsumen akan memimpin produk mereka di pasar selama beberapa tahun dengan terus berinovasi menciptakan keunggulan kompetitif (Kotler dan Keller, 2012).

Berdasarkan hasil penelitian yang dilakukan diperoleh data bahwa nilai $\mathrm{X}^{2}$ pada semua atribut dan merek produk yang diamati (varian rasa $=55,563 ;$ promosi $=32,667$; kemasan $=25,188$; jaminan $=30,375$; merek $=$ 101,438 ) lebih besar dari besarnya $X^{2}$ (varian rasa, kemasan, merek $>5,991$; promosi, jaminan $>$ 3,841). Artinya, preferensi konsumen terhadap kopi instan White Coffee di Kecamatan Kebumen tidak sama atau terdapat perbedaan preferensi konsumen terhadap pembelian kopi instan White Coffee.

Sikap konsumen terhadap objek kopi instan White Coffee didasarkan pada penilaian konsumen terhadap atribut-atribut yang dimiliki oleh kopi instan White Coffee tersebut. Penilaian yang dimaksud menyangkut dua hal, yaitu keyakinan (belief) bahwa kopi instan White Coffee memiliki atribut tertentu dan evaluasi terhadap atribut tersebut.

Tabel 6 menunjukkan atribut yang diyakini paling disukai oleh konsumen adalah merek atau dapat dikatakan bahwa konsumen mempunyai keyakinan bahwa kopi instan White Coffee yang dibeli oleh konsumen sesuai dengan kategori merek yang mereka sukai.

Tabel 6. Keyakinan Konsumen (bi) terhadap Atribut Kopi Instan White Coffee

\begin{tabular}{|c|c|c|c|c|c|c|c|}
\hline \multirow{3}{*}{ Atribut } & \multicolumn{5}{|c|}{ Nilai } & \multirow{3}{*}{ Nilai Total } & \multirow{3}{*}{ Rata-rata } \\
\hline & (SB) & (B) & (C) & (TB) & (STB) & & \\
\hline & 5 & 4 & 3 & 2 & 1 & & \\
\hline \multirow{2}{*}{ Varian Rasa } & 24 & 57 & 14 & 0 & 1 & 96 & \\
\hline & 120 & 228 & 42 & 0 & 1 & 391 & 4,07 \\
\hline \multirow{2}{*}{ Promosi } & 18 & 60 & 17 & 1 & 0 & 96 & \\
\hline & 90 & 240 & 51 & 2 & 0 & 383 & 3,99 \\
\hline \multirow{2}{*}{ Kemasan } & 15 & 61 & 17 & 3 & 0 & 96 & \\
\hline & 75 & 244 & 51 & 6 & 0 & 377 & 3,92 \\
\hline \multirow{2}{*}{ Jaminan } & 18 & 56 & 21 & 0 & 1 & 96 & \\
\hline & 90 & 224 & 63 & 0 & 1 & 377 & 3,94 \\
\hline \multirow{2}{*}{ Merek } & 39 & 49 & 7 & 1 & 0 & 96 & \\
\hline & 195 & 196 & 21 & 2 & 0 & 414 & 4,31 \\
\hline
\end{tabular}

Sumber : Analisis Data Primer, 2017 
Sedangkan atribut kopi instan White Coffee yang kurang disukai oleh konsumen adalah kemasan.

Tabel 7 menunjukkan bahwa merek kopi instan White Coffee merupakan atribut yang mempunyai tingkat kepentingan paling tinggi dalam keputusan pembelian kopi instan White Coffee atau konsumen menganggap bahwa atribut merek adalah atribut yang paling utama atau penting untuk diperhatikan dalam menentukan keputusan pembelian kopi instan White Coffee.

Perkalian antara angka penilaian keyakinan (bi) dan nilai evaluasi konsumen (ei) terhadap atribut kopi instan White Coffee menghasilkan indeks sikap konsumen (Ao). Angka ini menunjukkan penilaian konsumen terhadap atribut yang melekat pada kopi instan White Coffee yang meliputi varian rasa, promosi, kemasan, jaminan, dan merek kopi instan White Coffee.
Berdasarkan Tabel 8 dapat diketahui bahwa nilai indeks sikap konsumen terhadap atribut yang dipertimbangkan dalam keputusan pembelian terhadap kopi instan White Coffee berturut-turut dari yang paling tinggi sampai yang terendah adalah merek, varian, jaminan, promosi, dan kemasan. Sehingga dapat dikatakan, bahwa atribut merek merupakan atribut yang paling dipertimbangkan oleh konsumen dalam keputusan pembelian kopi instan White Coffee. Konsumen biasanya dalam melakukan pembelian kopi instan White Coffee lebih memperhatikan atribut merek karena apabila konsumen sudah merasa puas terhadap produk dengan merek tertentu, maka dia akan melakukan pembelian ulang atas produk tersebut dengan merek yang sama. Hal tersebut tidak lepas dari produk kopi instan White Coffee itu sendiri, apakah produk yang ada terkenal dipasar dan dikenal oleh konsumen atau tidak.

Tabel 7. Evaluasi Konsumen (ei) terhadap Atribut Kopi Instan White Coffee

\begin{tabular}{|c|c|c|c|c|c|c|c|}
\hline \multirow{3}{*}{ Atribut } & \multicolumn{5}{|c|}{ Nilai } & \multirow{3}{*}{ Nilai Total } & \multirow{3}{*}{ Rata-rata } \\
\hline & (SP) & (P) & (C) & (TP) & (STP) & & \\
\hline & 5 & 4 & 3 & 2 & 1 & & \\
\hline \multirow{2}{*}{ Varian } & 25 & 56 & 15 & 0 & 0 & 96 & \\
\hline & 125 & 224 & 45 & 0 & 0 & 394 & 4,10 \\
\hline \multirow{2}{*}{ Promosi } & 21 & 51 & 22 & 2 & 0 & 96 & \\
\hline & 105 & 204 & 66 & 4 & 0 & 379 & 3,95 \\
\hline \multirow{2}{*}{ Kemasan } & 23 & 50 & 21 & 2 & 0 & 96 & \\
\hline & 115 & 200 & 63 & 4 & 0 & 382 & 3,98 \\
\hline \multirow{2}{*}{ Jaminan } & 39 & 39 & 17 & 0 & 1 & 96 & \\
\hline & 195 & 156 & 51 & 0 & 1 & 403 & 4,20 \\
\hline \multirow{2}{*}{ Merek } & 36 & 47 & 13 & 0 & 0 & 96 & \\
\hline & 180 & 188 & 39 & 0 & 0 & 407 & 4,24 \\
\hline
\end{tabular}

Sumber : Analisis Data Primer, 2017

Tabel 8. Nilai Indeks Sikap Konsumen terhadap Kopi Instan White Coffee di Kecamatan Kebumen Kabupaten Kebumen

\begin{tabular}{lcccc}
\hline \multicolumn{1}{c}{ Atribut } & Keyakinan (bi) & Evaluasi (ei) & Sikap (Ao) & Peringkat \\
\hline Varian Rasa & 4,07 & 4,10 & 16,69 & II \\
Promosi & 3,99 & 3,95 & 15,76 & IV \\
Kemasan & 3,92 & 3,98 & 15,60 & V \\
Jaminan & 3,94 & 4,20 & 16,55 & III \\
Merek & 4,31 & 4,24 & 18,27 & I \\
\hline
\end{tabular}

Sumber : Analisis Data Primer, 2017 
Berdasarkan tabel 8 diketahui besarnya indeks sikap konsumen sehingga dapat diketahui bahwa atribut yang paling dipertimbangkan oleh konsumen dalam pembelian kopi instan White Coffee adalah atribut merek.

Atribut merek merupakan atribut yang paling dipertimbangkan oleh konsumen kopi instan White Coffee di Kecamatan Kebumen dalam proses pengambilan keputusan pembelian kopi instan White Coffee. Konsumen cenderung memilih merek sebagai pertimbangan pertama karena tidak lepas dari sejauh mana konsumen mengenal merek kopi instan White Coffee yang ada di pasar. Merek merupakan simbol atau indikator kualitas dari sebuah produk atau jasa, merek dikenal oleh konsumen dapat menjadi citra bahkan simbol status bagi produk tersebut. Maka merek pun dipertimbangkan sebagai alat evaluasi suatu produk. Oleh karena itu merek sangat dipertimbangkan dalam keputusan pembelian kopi instan White Coffee.

Atribut kedua yang dipertimbangkan oleh konsumen dalam proses pengambilan keputusan pembelian kopi instan White Coffee adalah varian rasa. Pemilihan varian rasa erat kaitannya dengan rasa yang disukai. Hal ini dikarenakan pertimbangan rasa terhadap suatu produk dapat menjadi indikator bagi seseorang untuk menyukai produk tersebut atau tidak. Apabila rasa kopi instan White Coffee tidak sesuai dengan keinginan dan selera, maka konsumen enggan untuk membelinya. Bagi sebagian besar konsumen saat ini varian merupakan atribut yang penting dan mempengaruhi mereka dalam mengkonsumsi produk minuman di samping dengan atribut lainnya yang ada.

Atribut ketiga yang dipertimbangkan konsumen dalam keputusan pembelian kopi instan White Coffee di Kecamatan Kebumen adalah jaminan. Jaminan menunjukkan bentuk tanggungjawab yang diberikan perusahaan kepada konsumen yang dikenakan pada produk yang akan dibeli konsumen. Adanya jaminan yang jelas terhadap suatu produk akan membuat konsumen merasa yakin untuk membeli produk yang mereka inginkan. Selain itu, adanya jaminan juga menunjukkan bahwa produk tersebut layak dipasarkan. Terkadang ada isu negatif yang beredar di konsumen terkait jaminan terhadap suatu produk yang akhirnya membuat konsumen ragu untuk membeli produk tersebut. Namun, dengan adanya jaminan yang jelas terhadap produk tersebut akan membuat konsumen yakin terhadap produk yang akan mereka pilih dan akhirnya mau melakukan pembelian terhadap produk tersebut.

Atribut keempat yang dipertimbangkan konsumen dalam keputusan pembelian kopi instan White Coffee di Kecamatan Kebumen adalah promosi. Promosi merupakan upaya bagaimana mendekatkan dan mengenalkan produk kepada konsumen, bagaimana cara membujuk konsumen untuk membeli produknya. Namun, promosi tidak menjadi atribut yang cukup dipertimbangkan oleh responden di Kecamatan Kebumen untuk membeli kopi instan White Coffee. Meskipun demikian, masih ada beberapa responden yang mempertimbangkan atribut tersebut sebelum melakukan pembelian, khususnya pada promosi yang memberikan bonus dalam pembeliannya, karena hal ini akan membuat konsumen mendapatkan kopi instan White Coffee dalam jumlah yang lebih dengan harga yang relatif sama.

Atribut terakhir yang dipertimbangkan konsumen dalam pembelian kopi instan White Coffee di Kecamatan Kebumen adalah kemasan. Atribut ini dapat diamati secara langsung sehingga mudah bagi konsumen mempertimbangkan keputusan pembelian dengan atribut ini. Meskipun demikian, kemasan merupakan atribut yang tidak begitu dipertimbangkan oleh konsumen dalam keputusan pembelian karena kopi instan White Coffee sulit dibedakan bagaimana kemasan yang disukai konsumen dan bagaimana yang tidak. Selain itu penjual dalam memasarkan kopi instan White Coffee, tidak membedakan kopi instan White Coffee yang dijualnya berdasarkan karakteristik kemasannya.

\section{KESIMPULAN DAN SARAN}

\section{Kesimpulan}

Kesimpulan yang dapat diambil dari hasil penelitian ini adalah : (1) konsumen terhadap pembelian kopi instan White Coffee di Kecamatan Kebumen Kabupaten Kebumen berdasarkan atribut yang ada yaitu varian rasa = original; promosi = bonus pembelian; kemasan = tampilan menarik; dan jaminan = halal; serta 
produk yang disukai adalah merek Luwak White Koffie.(2) Atribut kopi instan White Coffee yang paling dipertimbangkan dalam keputusan pembelian kopi instan White Coffee di Kecamatan Kebumen Kabupaten Kebumen adalah atribut merek dengan urutan atribut dari yang paling dipertimbangkan sampai dengan yang kurang dipertimbangkan adalah atribut merek, varian rasa, jaminan, promosi, dan kemasan.

\section{Saran}

Berdasarkan kesimpulan yang diperoleh dari penelitian ini, saran yang dapat diberikan adalahadalah : (1) Produsen kopi instan White Coffee sebaiknya melakukan strategi pemasaran yang disukai oleh konsumen, karena hal tersebut akan membuat produk lebih potensial untuk dibeli konsumen. (2) Produsen kopi instan White Coffee terus melakukan branding terhadap produk mereka sehingga akan meningkatkan citra merek dan membuatnya lebih dikenal oleh konsumen, karena merek merupakan atribut yang paling dipertimbangkan konsumen, khususnya di Kecamatan Kebumen.

\section{DAFTAR PUSTAKA}

Arianty D dan Rohmana Y. 2012.Faktor-Faktor Yang Mempengaruhi Preferensi Konsumen Provider Indosat di Perguruan Tinggi Negeri Kota Bandung.Jurnal Sains dan Terapan, 7 (2): 1-12.

Darmawan D. 2013.Metode Penelitian Kuantitatif.PT Remaja Rosdakarya. Bandung.

Hedynata M dan Radianto W. 2016.Strategi Promosi dalam Meningkatkan Penjualan Luscious Chocolate Potato Snack.Jurnal Manajemen dan Start-Up Bisnis, 1 (1) : 87-96.

Indarto R. 2011. Analisis Preferensi Konsumen Terhadap Building Kartu GSM Dengan Smartphone (Studi Bulding Smartphone
Oleh Telkomsel dan XL). Tesis. Universitas Indonesia Press. Jakarta.

Khamidi S. 2013. Pengaruh Diversifikasi Produk Terhadap Penjualan (Studi Kasus Pada Perusahaan Konveksi "Faiza Bordir" Bangil-Pasuruan). Jurnal Administrasi Bisnis, 5(2) : 1-8.

Kotler P dan Keller K. 2012. Marketing Management 14e. Global Edition. Pearson Prentice Hall.

Kurniawan.2014. Tanggung Jawab Pelaku Usaha terhadap Pemberian Label Halal pada Produk Makanan dan Minuman Perspektif Hukum Perlindungan Konsumen. Jurnal Penelitian UNRAM, 18 (1): 80-96.

Marion A. 2015. Hubungan Antara Citra Merek (Brand Image) Kopi Kapal Api dengan Perilaku Konsumen. Prosiding Hubungan Masyarakat Seminar Penelitian Sivitas Akademika Unisba, 1 (1): 416-426.

Nuryanti B dan Rahman A. 2008. Pengaruh Variasi dan Kemasan Produk terhadap Keputusan Pembelian The Kotak Ultrajaya (Survei pada Mahasiswa FPIPS Universitas Pendidikan Indonesia). Jurnal Strategic, 7 (14): 31-43.

Putri N dan Iskandar D. 2014. Analisis Preferensi Konsumen Dalam Menggunakan Social Messenger Di Kota Bandung (Studi Kasus : Line, Kakaotalk, Wechat, Whatsapp). Jurnal Manajemen Indonesia, 14 (2): 110-127.

Surakhmad W. 2004.Pengantar Penelitian Ilmiah Dasar Metode Teknik. Tarsito. Bandung.

Zamhir.2014. Analisis Preferensi Konsumen terhadap Produk Air Minum dalam Kemasan (Studi Di Perumahan Graha Pandaan). Jurnal Ilmiah, 3 (1): 1-12. 